AperTO - Archivio Istituzionale Open Access dell'Università di Torino

\title{
Geophysical characterization of an instable rock mass
}

\section{This is the author's manuscript}

Original Citation:

\section{Availability:}

This version is available http://hdl.handle.net/2318/144719

since

Publisher:

CRC Press - Taylor \& Francis Group

Terms of use:

Open Access

Anyone can freely access the full text of works made available as "Open Access". Works made available under a Creative Commons license can be used according to the terms and conditions of said license. Use of all other works requires consent of the right holder (author or publisher) if not exempted from copyright protection by the applicable law. 


\title{
Geophysical Characterization of an Instable Rock Mass
}

\author{
C. Colombero \& C. Comina \\ Earth Science Department, University of Torino, Torino, Italy
}

\begin{abstract}
A pre-requisite in rock mass stability analysis is to obtain the internal structure and the mechanical properties of the investigated rock mass with a reasonable degree of uncertainty. In this respect, geophysical methods can be profitably used as an imaging and characterization tool. Seismic methods are often more suitable because the measurements depend on the mechanical properties of the rock mass. The present paper presents the use of cross-hole seismic tomography in a site (Madonna del Sasso - NW Italy) affected by a rock instability phenomenon, highlighted by episodes of slow deformation recorded by standard measurement devices. Geophysical tests have been fundamental in imaging the fracturing state and the relative variation of seismic velocities between intact an altered rock and in defining the seismic velocity field of the rock mass, a basic prerequisite for the future planned microseismic monitoring step.
\end{abstract}

\section{INTRODUCTION}

A common task in slope and rock mass stability and landslides studies is to retrieve the internal structure and the mechanical properties of the material involved in the gravitative phenomenon. It is indeed of major importance to determine the geometry of slope instabilities (particularly in respect to the position of the sliding surface and the orientation of the main fracture systems) in order to facilitate reliable analysis and mitigation. Focusing on the gravitative processes that affect rock masses, an important prerequisite for the stability analysis is a good knowledge of the fracturing state, with particular reference to orientation, spacing, opening and persistence, filling and hydraulic conditions of the discontinuities. All these elements have a peculiar influence in the behavior of the sliding mass.

These parameters can be obtained by means of the extrapolation of geological and geomechanical observations and classical measurements of the fracture state on the external surfaces of the rock mass. However, geophysical methods for a direct imaging of the internal structure of the rock mass can also be profitably applied.

Among the available geophysical methods, seismic surveys are often more suitable to infer the internal structure of the sloping body (Bruno and Marillier, 2000; Mauritsch et al., 2000; Heincke et al.,
2006; Maurer et al., 2010) because the measurements principally depend on the mechanical properties of the rock mass, that are also important in the numerical simulation of slope stability analysis. Seismic surveys can be executed both from the surface (seismic reflection and seismic refraction tomography) and in hole (down-hole or cross-hole tests). Usually in-hole surveys allow reaching greater penetration in respect to surface tests when the space for testing is limited (like it is commonly in case of steep rock masses).

Particularly, in cross-hole seismic tomography, seismic sources are located both in well and on the ground surface and are shot in receivers that are placed in a nearby well or on the same surface. The travel times of the first arrivals are then used to produce a tomographic velocity cross-section of the subsurface between the two boreholes (Bregman et al., 1989; Calnan and Schuster, 1989; Lines and LaFehr, 1989; McMechan et al., 1987). Cross-hole tomography is expected to provide better resolution than surface-based seismic methods, since most of the energy does not travel through the highlyattenuating near surface and the travel distances are shorter. In addition, the resolution of cross-hole tomography is not depth-limited since most of the energy travels between the wells and a transillumination of the imaged medium is achieved. This is even more important in fractured media where waves can follow complicated travel paths, not easily interpretable only from the surface. 
In the present paper we present the results of the application of cross-hole seismic tomography as a characterization tool in the site of Madonna del Sasso (Verbania, NW Italy), affected by a rock instability phenomenon highlighted by neat and long lasting episodes of slow deformation recorded by standard monitoring devices (topographic measurements, borehole inclinometers, crackmeters and extensometers).

The site was chosen for the installation of a microseismic monitoring network based on the recording and analysis of acoustic emissions related to micro-cracking processes inside the rock mass. A detailed geophysical and geomechanical characterization of the test site was therefore required in order to define the overall geometry and the fracturing state of the instable rock mass and to establish the best position of the nodes for the monitoring network. Furthermore the definition of the seismic velocity field inside the rock mass is a fundamental parameter for the processing of the recorded microseismic signals, in order to localize the sources of acoustic emissions.

The seismic results were compared with the outcomes of previous geomechanical surveys, continuous borehole cores and the available mapping of the fracture systems affecting the rock mass, in order to better define the internal characteristics of the monitored rock slide and to image the fracturing state and the relative variation in seismic velocities between altered and intact rock.

\section{THE SITE}

The cliff of Madonna del Sasso $\left(45^{\circ} 79^{\prime} \mathrm{N}, 8^{\circ} 37^{\prime} \mathrm{E}\right)$ is located in NW Italy, SW the city of Verbania, on the western shore of the Orta Lake (Figure 1a). It is a high massive granite outcrop bordered on three sides $(\mathrm{N}, \mathrm{E}$ and $\mathrm{S})$ by roughly vertical walls, with a height of about $200 \mathrm{~m}$ (Figure 1b).

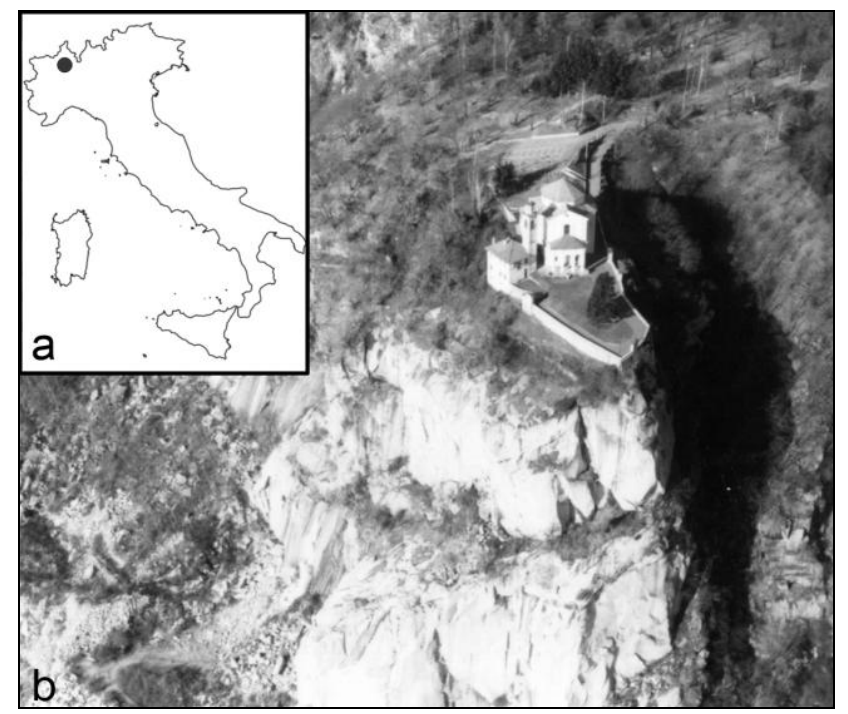

Figure 1. Geographical location (a) and general view (b) of the cliff of Madonna del Sasso (VB, NW Italy).
The top of the relief is located at an altitude of approximately $650 \mathrm{~m}$ a.s.l. and it is occupied by a panoramic square, in front of the eighteenth-century sanctuary, from which the place takes its name.

From a geological point of view the area is totally characterized by a granitic rock mass, known as Granito di Alzo. The actual morphology is the result of a strong mining activity conducted in the past.

A preliminary rock mass characterization was carried out by means of a conventional survey (Lancellotta et al., 1991) and leaded to define the rock mass as intact or massive, with widely spaced discontinuities $(G S I>70)$ and characterized by good surface quality. Four main joint sets have been identified: $K 1$ (110/75), K2 (0/80), K3 (150/15) and $K 4(50 / 75)$ and are depicted in a planar view in Figure 2a. These discontinuities tend to isolate the north-west frontal portion of the cliff which increases its instability as a function of the rock joints along the fractures and its foot constraint. A volume of about $12,000 \mathrm{~m}^{3}$ has been estimated for this instable sector. Particularly along a $K 4$ discontinuity there is a clear evidence of movement: a decimetric step is clearly visible on the yard and in the small confining walls in front of the sanctuary (Figure 2a).

Two inclinometric boreholes, S1 and S2, have been placed in past years in the front yard of the sanctuary (Figure 2a) revealing rock mass oscillations that can be related to seasonal trends. Core logs from these boreholes confirmed the presence of altered/fractured granite in correspondence of the revealed joint sets, particularly along the $K 4$ plane (Figure 5).

\section{GEOPHYSICAL INVESTIGATION}

A cross-hole seismic tomography was performed in the area in front of the sanctuary, between the two available inclinometric boreholes (Figure 2a).

To perform the tests a Borehole Impacter Source by Geotomographie $\mathrm{GmbH}$ was used as in-hole source in the $\mathrm{S} 2$ borehole, with three different locations till a depth of about $6 \mathrm{~m}$ (after this depth an obstruction of the hole casing inhibited further penetration) while a hammer, impinging both vertically and horizontally on a steel rod, was employed as surface source in three different locations along the line connecting the two holes (Figure 2b).

A prototype borehole string equipped with 8 three-component geophones $(10 \mathrm{~Hz})$ at $1 \mathrm{~m}$ spacing, stiffly connected by a PVC bar that permits to control geophone orientation, was progressively lowered (with a 2 geophone superposition each subsequent positioning) in the S1 sounding at different depths, till the maximum available depth of $27 \mathrm{~m}$. On the yard surface 4 three-component geophones $(2 \mathrm{~Hz})$ were placed along the line connecting the two boreholes, with a reciprocal spacing of $2.5 \mathrm{~m}$ (Figure $2 \mathrm{~b}$ ). 
First break manual picking was performed on the acquired seismic traces, on the pertaining components, to allow for both $\mathrm{P}$ - and S-wave velocities imaging. Data were inverted to obtain a tomographic image between the investigated volume with the use of GeoTomCG software, which performs threedimensional tomographic analysis with source and receiver positions in any configuration within a 3-D grid. The software allows for curved-ray calculations which have been observed to be more accurate in case of strong velocity contrasts. Curved ray tracing is performed with a revised form of ray bending, derived from the Um and Thurber (1987) method. Inversions are performed with the simultaneous iterative reconstruction technique (SIRT, Lytle et al., 1978; Peterson et al., 1985).

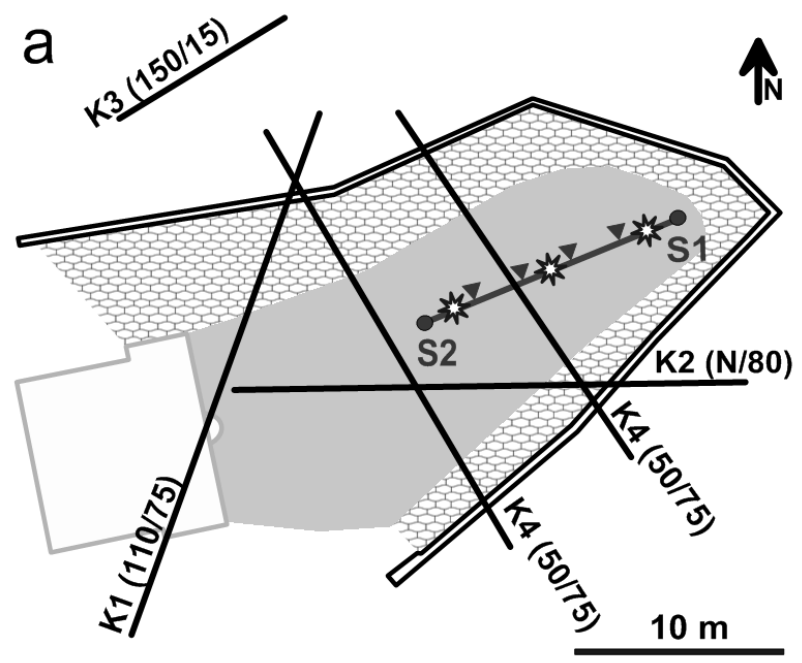

b

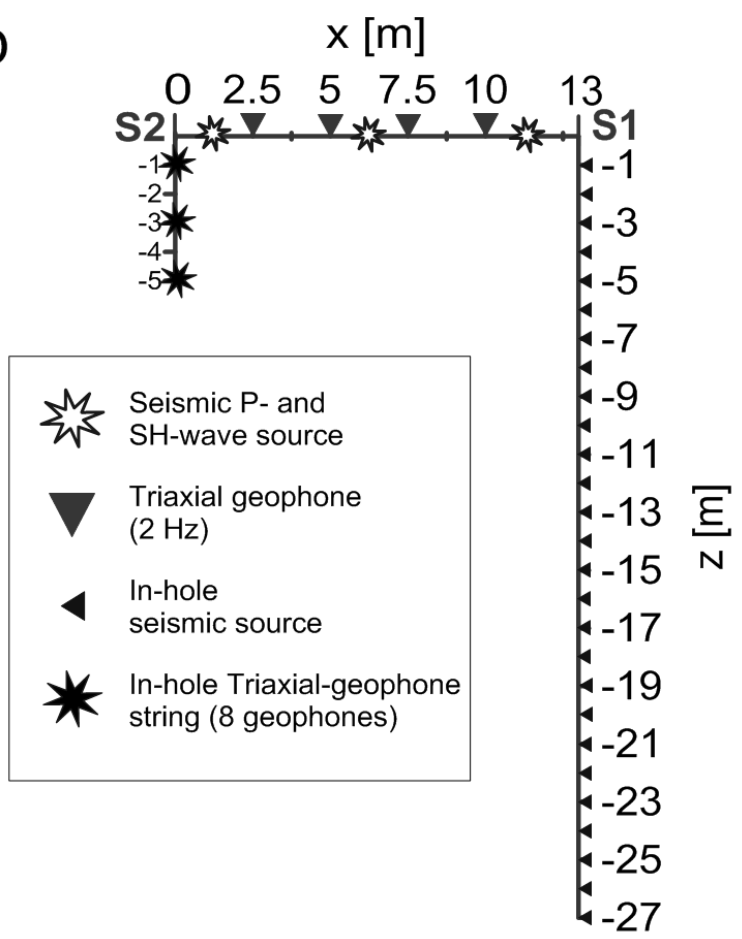

Figure 2. Sketch of the front yard of Madonna del Sasso site, in which the main traces of the fracture systems and the inclinometric boreholes positions are reported (a). Acquisition scheme for the cross-hole seismic tomography survey (b).

\section{RESULTS AND DISCUSSION}

The $\mathrm{P}$ - and S-wave velocity images obtained from cross-hole seismic tomography are reported in Figure 3 and 4, together with the ray coverage resulting from the inversion.
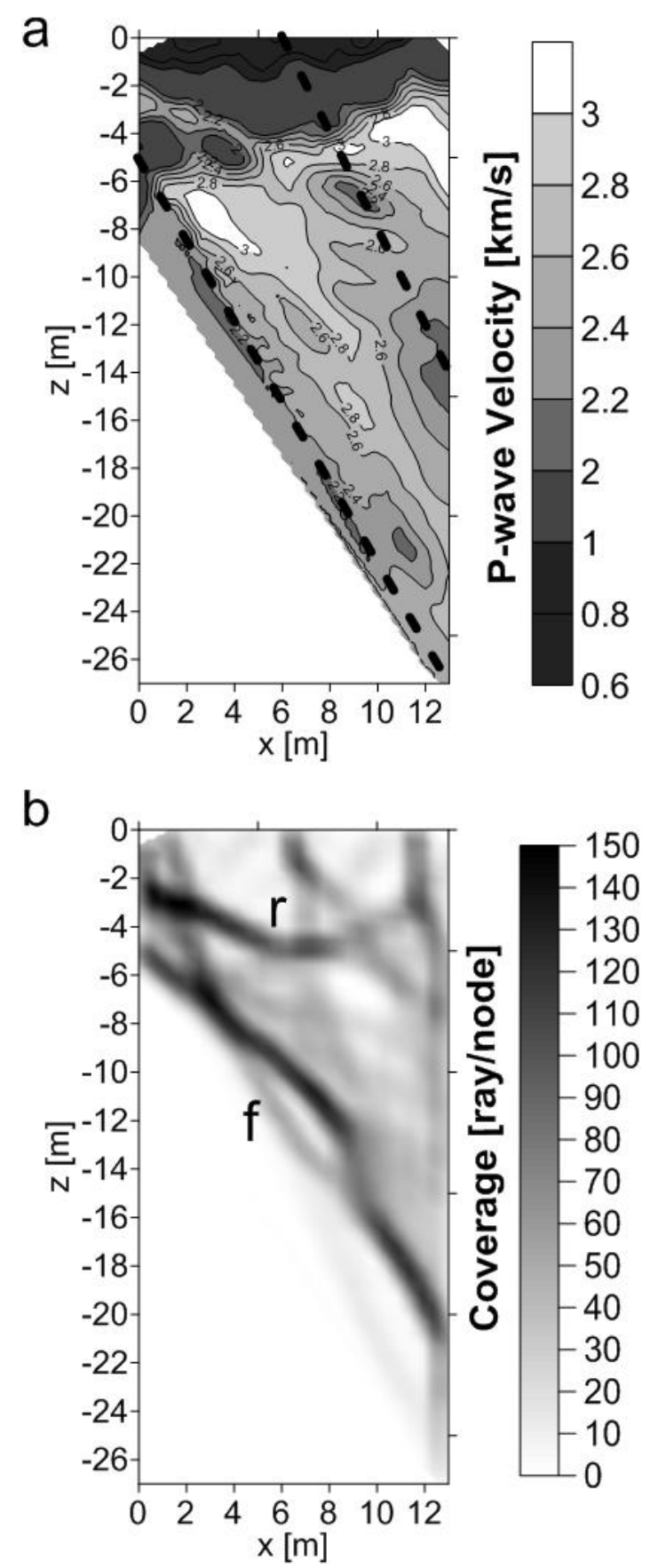

Figure 3. Results of the cross-hole seismic tomography for $\mathrm{P}$ waves: velocity (a) and ray coverage (b) sections.

In both $\mathrm{P}$ and $\mathrm{S}$ section a shallow coverage of low velocity materials of about $2 \mathrm{~m}$ (top soil and highly altered/fractured granite, as also resulting from core $\operatorname{logs}$ ) is evidenced. A clear refraction boundary ( $\mathrm{r}$ in Figure $3 \mathrm{~b}$ and $4 \mathrm{~b}$ ) is noticed below this zone revealing an interface with a high-velocity but nonhomogeneous granite formation. Intact granite velocity reaches about $2.6-3.0 \mathrm{~km} / \mathrm{s}$ for $\mathrm{P}$ waves and $1.6-2.0 \mathrm{~km} / \mathrm{s}$ for $\mathrm{S}$ waves. 
Two main low-velocity zones (about 2.2-2.4 km/s for $\mathrm{P}$ waves and 1.4-1.2 m/s for $\mathrm{S}$ waves) are also evidenced in both seismic sections within the massive granite formation. Dip and inclination of these zones (approximated dashed lines in Figure $3 \mathrm{a}$ and 4a) compare well with the fractures of the $K 4$ system (50/75) whose traces are directly visible on the yard in front of the sanctuary. Their position on the front yard (Figure 2a) is also comparable to the one extrapolated from seismic map.
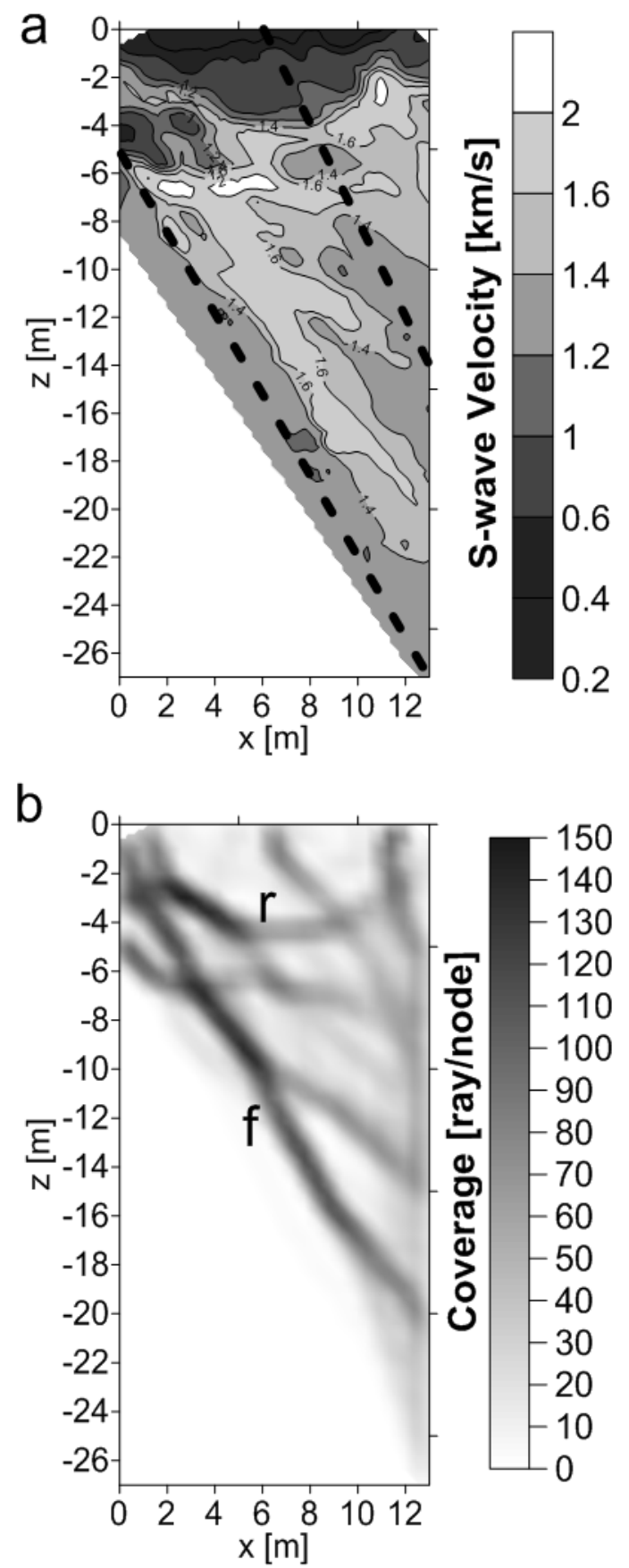

Figure 4. Results of the cross-hole tomography for S waves: velocity (a) and ray coverage (b) sections.

In both images the first (deepest one) of these low velocity zones is at the border of the investigated volume, in a low ray density zone, so that it has to be considered not completely reliable. Nevertheless it can be evidenced from the ray coverage that do not reach the deepest area of investigation, but concen- trate above the same, evidencing the presence of a high ray density zone (f in Figure $3 b$ and $4 b$ ). The second zone is instead located between the two boreholes, at a distance of about $6 \mathrm{~m}$ from $\mathrm{S} 2$, progressively deepening towards $\mathrm{S} 1$.

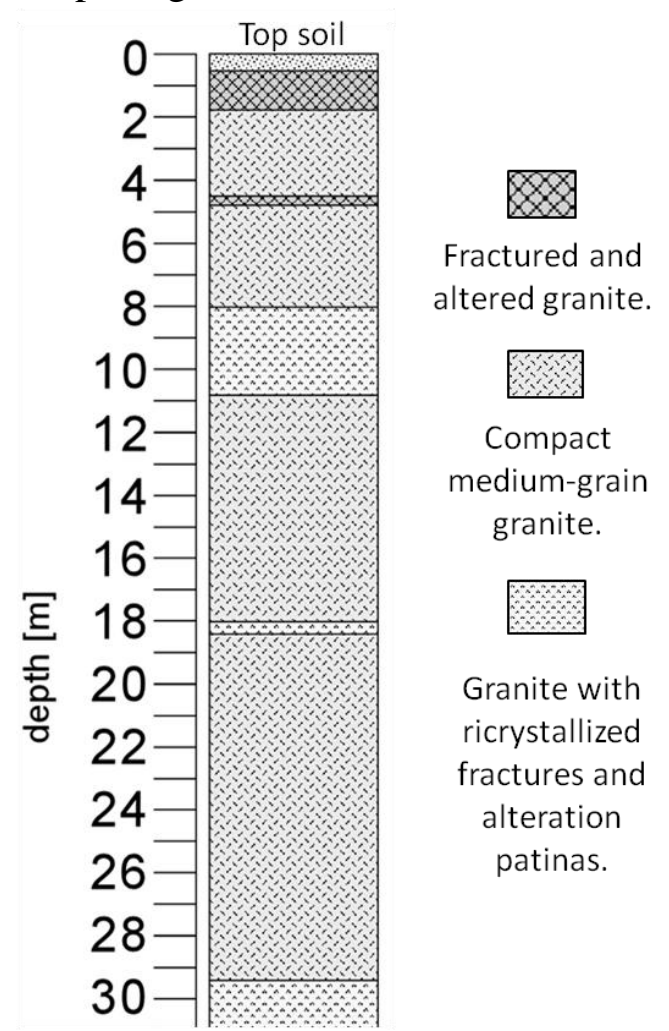

Figure 5. Technical borehole stratigraphic log of S1 sounding.

Low seismic velocities zones quite well compare with the outcomes of the stratigraphic log along the S1 sounding (Figure 5) enabling to associate the reduction in velocity values to zones of the rock mass with clear evidence of recrystallized fractures and alteration patinas. It must be considered that the sounding has been executed several years before the geophysical tests of this study so that reactivation or further fracturing may not be evidenced in the same way in the two surveys. Particularly for what concerns the deepest fracture plane, the velocity reduction zone seems to be shallower in respect to what depicted from the sounding (also considering that this is at the border of the investigated seismic volume). This sliding plane appears indeed to have the main evidences of movements (greater aperture and clear surface evidences) and could be considered the main cause of instability while the shallower fracture plane could be related to secondary movements of the rock mass and appears to have less surface evidences.

Given the accordance of all these evidences, the geophysical surveys reveal however a non-uniform sliding plane (related to the shape of the high density ray zone $f$ and to the variation of seismic velocities along it) probably associated with the presence of rock bridges whose ruptures could be the main cause of instability and which can be the object of the monitoring campaign. 


\section{CONCLUDING REMARKS AND FUTURE WORK}

This paper shows the first results of an ongoing work concerning the geophysical characterization of an instable rock mass, preliminary to the installation of a microseismic monitoring network.

The seismic survey allowed investigating in depth the fracturing state of the granite mass, in order to better understand the instability mechanism and to design the monitoring system that will be placed in the next future.

The geophysical results agree with the outcomes of the previous geomechanical analysis and the evidences from borehole logs locating the main source of instability of the rock cliff along a defined sliding plane ( $K 4$ discontinuity). Two main areas with lower $\mathrm{P}$ and $\mathrm{S}$ velocity are highlighted and seem to be well correlated with the fracture traces visible on the yard in front of the sanctuary and on the high cliff bordering the site. Outcomes of the geophysical surveys allowed us to better investigate the presence and nature of this interface revealing a non-uniform sliding plane probably associated with the presence of rock bridges whose ruptures could be the main cause of instability and can be monitored by means of acoustic emissions.

In order to obtain a three-dimensional model of the seismic velocity, basic requirement for the processing and location of the microseismic signals, further sections of cross-hole tomography will be acquired on the site, using another available inclinometric borehole and implementing the number and geometry of the network of surface geophones.

\section{ACKNOWLEDGEMENTS}

Geophysical tests of this study have been funded within the Progetto d'Ateneo 2012 - SAFER of Torino University: "Detecting Slow Deformation Signals Preceding Dynamic Failure: A New Strategy For The Mitigation Of Natural Hazards", supervised by Sergio Vinciguerra. Authors are indebted with Politecnico di Torino for the use of seismic instrumentation and interpretation software.
Calnan, C. \& Schuster, G.T. 1989. Reflection and transmission cross-well tomography. 59th Ann. Internat. Mtg., Soc. Expl. Geophys., Expanded Abstracts: 908-911.

Chen, S.T., Zimmerman, L.J. \& Tugnait, J.K. 1990. Subsurface imaging using reversed vertical seismic profiling and crosshole tomographic methods. Geophysics, 55: 1478-1487.

Heincke, B., Maurer, H., Green, A., Willenberg, H., Spillmann, T. \& Burlini, L. (2006). Characterizing an unstable mountain slope using shallow 2D and 3D seismic tomography. Geophysics, 71 (6): B241-B256. Doi: 10.1190/1.2338823.

Kwiatek, G. \& Ben-Zion, Y. 2013. Assessment of P and S wave energy radiated from very small shear-tensile seismic events in a deep South African mine. J. Geoph. Res.: Solid Earth, 118: 3630-3641. Doi: 10.1002/jgrb.50274.

Lancellotta, R., Gigli, P. \& Pepe, C. 1991. Relazione tecnica riguardante la caratterizzazione geologico-strutturale dell'ammasso roccioso e le condizioni di stabilità della rupe. Private communication.

Lines, L.R. \& LaFehr, E.D. 1989. Tomographic modeling of a cross-borehole data set. Geophysics, 54: 1249-1257.

Lytle, R.J., Dines, K.A., Laine, E.F. \& Lager, D.L. 1978. Electromagnetic Cross-Borehole Survey of a Site Proposed for an Urban Transit Station. UCRL-52484, Lawrence Livermore Laboratory, University of California, $19 \mathrm{pp}$.

Maurer, H., Spillmann, T., Heincke, B., Hauck, C., Loew, S., Springman, S.M. \& Green, A.G. 2010. Geophysical characterization of slope instabilities. First Break , 28 (8), Special topic: Near Surface Geoscience: 53-61.

Mauritsch, J.H., Seiberl, W., Arndt, R., Römer, A., Schneiderbauer, K. \& Sendlhofer, G.P. 2000. Geophysical investigations of large landslides in the Carnic Region of southern Austria. Eng. Geol., 56: 373-388

McMechan, G.A., Harris, J.M. \& Anderson, L.M. 1987. Crosshole tomography for strongly variable media with applications to scale model data. Bull. Seis. Soc. Am., 77: 19451960.

Peterson, J. E., Paulson, B.N.P. \& McEvilly, T.V. 1985. Applications of Algebraic Reconstruction Techniques to Crosshole Seismic Data. Geophysics, 50: 1566-1580.

Um, J., \& Thurber, C. 1987. A Fast Algorithm for Two-Point Seismic Ray Tracing. Bull. Seismol. Soc. Am., 77: 972-986.

\section{REFERENCES}

Bregman, N.D., Bailey, R.C. \& Chapman, C.H. 1989. Crosshole seismic tomography. Geophysics, 54: 200-215.

Bruno, F. \& Marillier, F. 2000. Test of high-resolution seismic reflection and other geophysical techniques on the Boup landslide in the SwissAlps. Surv. Geophys., 21: 333-348. 